\title{
A NEW MEXICAN GENUS AND SPECIES OF DINOCAMPINI WITH SERRATE ANTENNAE (HYMENOPTERA: BRACONIDAE: EUPHORINAE)*
}

\author{
By Scott Richard Shaw \\ Museum of Comparative Zoology, Harvard University, \\ Cambridge, Massachusetts 02138
}

The cosmopolitan braconid subfamily Euphorinae (sensu Shaw $1985,1987,1988)$ comprises 36 genera of koinobiont endoparasitoids, which parasitize the adult stages of holometabolous insects or nymphs and adults of hemimetabolous insects (Muesebeck 1936, 1963; Shenefelt 1980; Loan 1983; Shaw 1985, 1988). Occasionally the parasitoids of holometabolous insects will oviposit into larvae as well as adults (Smith, 1960; David \& Wilde, 1973; Semyanov, 1979), but this only occurs where larvae are ecologically coincident with adults, living and feeding on the same plants (Tobias, 1966). Obrycki et al. (1985) found that Dinocampus coccinellae (Schrank) will oviposit into all larval instars, and pupae, as well as adults; however, the highest percentage of successful parasitization occurred when adults were attacked. Only a few papers have discussed euphorines of Mexico in particular (Muesebeck 1955; Shaw 1987).

The euphorine tribe Dinocampini was defined by Shaw (1985, $1987,1988)$ to comprise three genera with ocular setae, antennal scape three times longer than wide, and labial palpus reduced to two segments. As far as is known, members of the tribe Dinocampini parasitize adult beetles; Dinocampus Foerster parasitizes Coccinellidae (Shenefelt 1980) and Ropalophorus Curtis parasitizes Scolytidae (Shenefelt 1960, Shaw 1988). The hosts of the third included genus, Centistina Enderlein, are not known. Because these genera are known only from females (Balduf 1926; Shenefelt 1960), it seems possible that females of the entire tribe are thelyotokous, reproducing parthenogenetically and producing only female progeny. The purpose of this paper is to describe a fourth genus of Dinocampini from Mexico. This new genus and species is remarkable because it has serrate antennae, unlike any other known braconid.

*Manuscript received by the editor November 14, 1988 
The morphological terminology used in this paper is mostly that of Shaw $(1985,1987)$ and van Achterberg (1974). Microsculpture terminology is that of Harris (1979). Flagellomeres, from base to apex, are abbreviated as F1 through F13.

\section{Genus Betelgeuse Shaw, NEW GENUS}

(Figs. 1-3)

Type species: Betelgeuse aztecus Shaw, n. sp.

Etymology: Following greek mythology, the constellation of Orion is depicted on astronomical charts as a sword-bearing hunter. Because females have a conspicuous sword-like ovipositor, this genus is named for the star Betelgeuse (pronounced "beetle-juice"), which is part of the constellation of Orion. The name is masculine.

Description: Head (Fig. 2) transverse, in dorsal view $2.3 \times$ broader than long; surface sculpture coarsely and evenly rugose; eyes elongate oval, not bulging anteriorly beyond frons; eyes in anterior view distinctly converging ventrally; shortest inter-ocular distance $2 \times$ clypeus width; minute ocular setae present; median frontal carina weakly present, extending from midpoint of face to between antennal insertions; inter-antennal distance $3.25 \times$ socket width; scrobes not protuberant; scape elongate, gradually curved, gradually wider apically; scape length $4 \times$ width at apex; pedicel somewhat globose; flagellum 13-segmented, considerably shorter than body length; F1-F5 longer than wide, gradually wider apically, somewhat flattened, forming serrations antero-laterally, each serration terminating apically in a sharp point and a single long seta; F1 $3 \times$ wider than apical width, F2-F5 each relatively shorter than preceding flagellomere; F6-F12 each compact, about as long as wide, segments gradually slightly thicker apically, each with a single long seta projecting dorso-apically; apical flagellomere $2 \times$ as long as wide, apically pointed; ocellar triangle small, distance between lateral ocellus and eye $4 \times$ distance between lateral ocelli; occipital carina complete; malar space short, slightly less than $1 / 4$ eye height; malar suture indistinct; facial setae minute, not obscuring face; lower clypeal margin truncate; mandibles when closed overlapping for slightly less than half mandible length; maxillary palpus 5segmented; labial palpus 2-segmented.

Mesosoma with surface sculpture entirely coarsely rugose to rugo-punctate; notaulus and sternaulus indistinct from general 


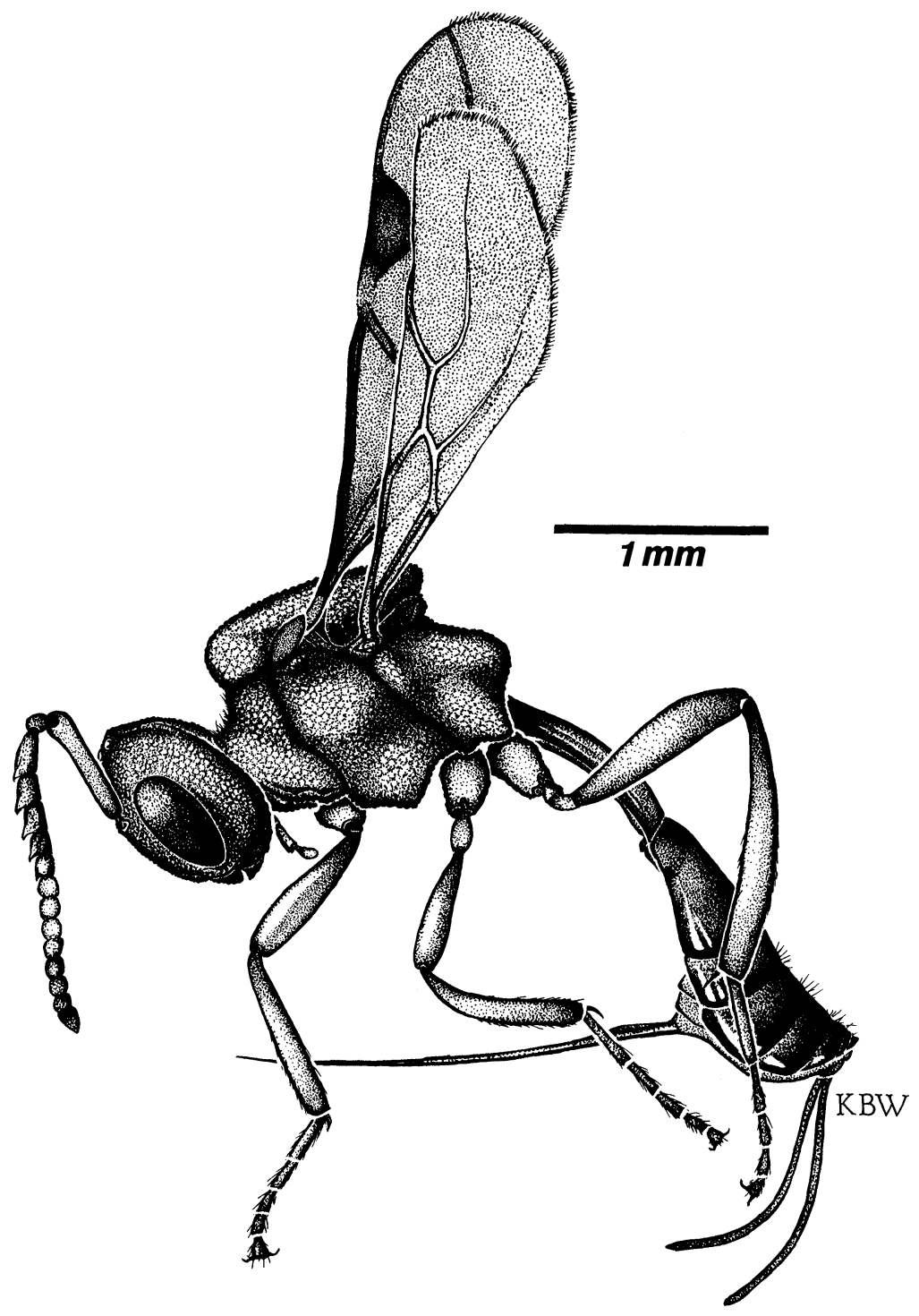

Fig. 1. Betelgeuse aztecus, lateral habitus. 
rugose sculpture; scutellar furrow 10 -foveate, cross-carinae present; anterior margin of scutellar furrow carinate; propodeum rugoareolate; propodeal impression present, as deep as basal width of petiole; postero-lateral corners of propodeum developed as prominent tubercles; petiolar notch short, not extending past metacoxal cavity; hind leg except tarsus coarsely granular; metafemur length $4.25 \times$ maximum width; tarsal claw simple.

Wings as in Fig. 3; stigma large, nearly semi-circular; basal vein gradually curved; second intercubitus absent; second cubital abscissa present; discoideus present; brachius present; first intercubitus present; radius reaching wing margin slightly before wing apex, radial cell longer than stigma; radius complete to wing margin, but more weakly sclerotized apically; metacarpus present, but very weakly sclerotized; recurrent vein present; subdiscoideus present; first cubital abscissa absent; nervulus postfurcal, bisecting discocubital cell; medius present; submediella present; nervellus present; costella present; radiella and cubitella present as weak infumation.

Metasoma with petiole not fused ventrally, smooth dorsally, rugose laterally, apex $4 \times$ broader than base, about $3 / 4$ as long as metasoma beyond petiole excluding ovipositor; glymma absent; dorsope absent; petiolar spiracles near middle of petiole, moderately prominent; syntergum $2+3$ shorter than $3 / 4$ length of metasoma beyond petiole excluding ovipositor, several following segments exposed; sides of syntergum $2+3$ not overlapping ventrally; lateral fold of syntergum $2+3$ present; suture between terga $2+3$ present laterally; ovipositor $0.94 \times$ as long as metasoma; sheaths shorter, about $0.56 \times$ as long as metasoma.

Diagnosis: In the key to genera of Euphorinae of the world by Shaw (1985) Betelgeuse will run to couplet 29, but will not key further because the scape configuration does not match either of the two alternatives at that point. In the identification manual for North American genera of Braconidae (Marsh et. al 1987) Betelgeuse will run to couplet 212, where it keys out near Ecclitura Kokujev from which Betelgeuse can be distinguished by its distinctive serrate antenna. Indeed, it can be distinguished from any other braconid genus by this character alone.

Phylogeny: The phylogeny of euphorine genera was reviewed by Shaw $(1985,1987)$. Because the fore wing lacks the first segment of 

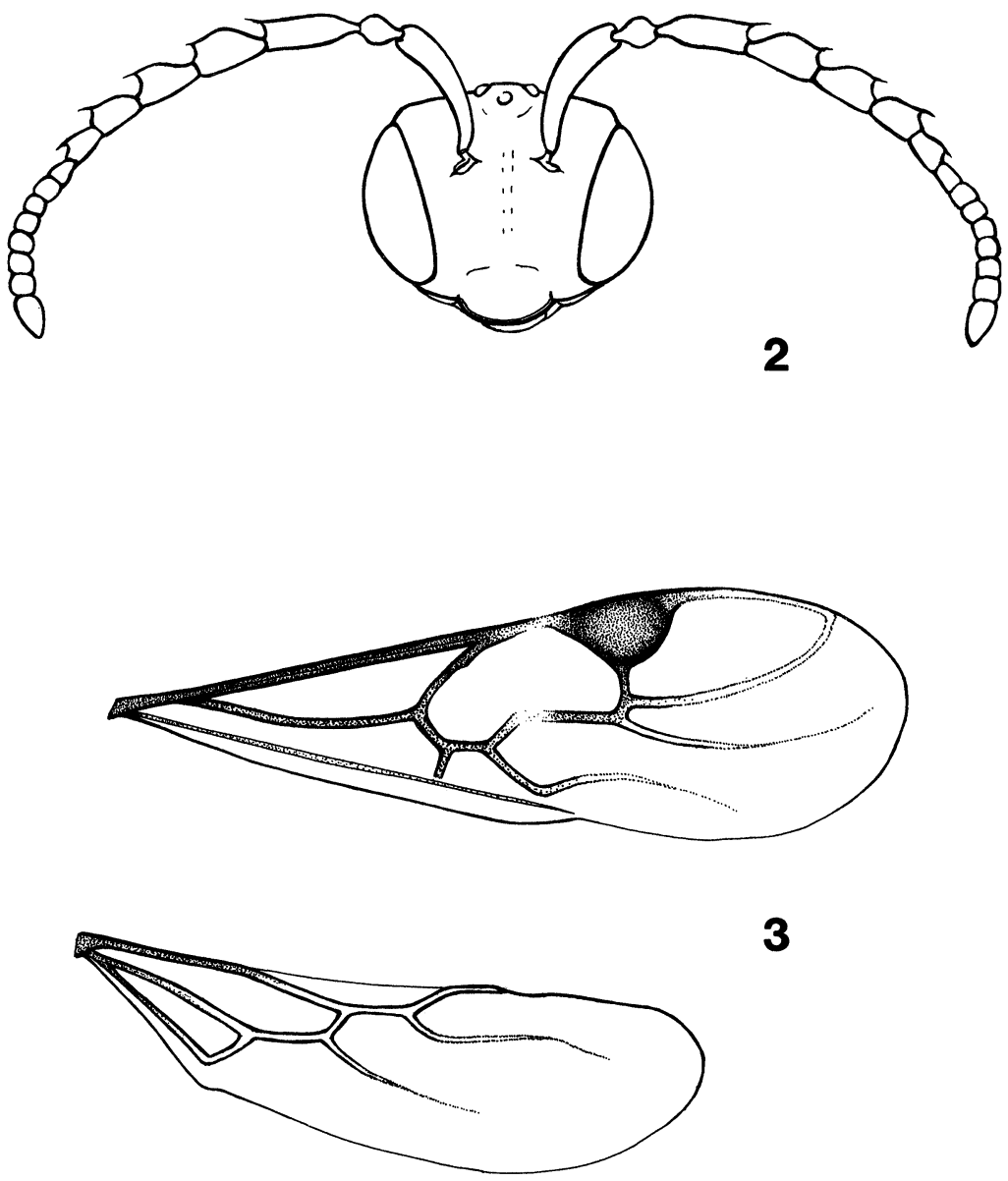

3

Fig. 2. Betelgeuse aztecus, head in anterior view.

Fig. 3. Betelgeuse aztecus, wings.

the cubitus, the phylogenetic position of Betelgeuse is not immediately obvious. The loss of this vein is synapomorphy defining the euphorine Section 3 (sensu Shaw 1985) cluster of tribes; however, Betelgeuse lacks the other three synapomorphies that define that 
group: smooth mesopleuron, smooth scutellar disc, and carinaterugulose propodeum. Furthermore, Betelgeuse does have a suite of synapomorphies which place it in the Section 2 tribe Dinocampini (sensu Shaw 1985): deep propodeal impression, coarse frontal sculpture, minute ocular setae, elongate scape, and 2-segmented labial palpus. In view of this, I regard Betelgeuse as a member of the Dinocampini, which has lost the first segment of the cubitus (a convergence with Section 3 genera). Within the Dinocampini, Betelgeuse has two synapomorphies of the lineage comprising Dinocampus + Ropalophorus: wide face, and areolate propodeum. At least two putative synapomorphies suggest a sister-group relationship with Ropalophorus: flagellum reduced to 13 segments or less (8 in Ropalophorus), and propodeum produced dorso-laterally as distinct tubercles. The latter is particularly convincing as a synapomorphy since it does not occur elsewhere in the Euphorinae, and was previously known only in Ropalophorus. The monophyly of Ropalophorus remains indicated by its 8-segmented clavate flagellum (Shaw, 1985). These relationships are expressed as a cladogram (Fig. 4) modified from Shaw (1985, 1987).

\section{Betelgeuse aztecus, NEW SPECIES}

(Figs. 1-3)

Holotype. Female, Mexico: Durango, $9000^{\prime}$, El Salto, 10 mi. W., 8 June 1964, (W.R.M. Mason). [Canadian National Collection, Ottawa]

Diagnosis of holotype female: Body length $3.83 \mathrm{~mm}$; forewing length $2.92 \mathrm{~mm}$; flagellomere length ratios (F1-F13) 19:14:12:11:9: 6:5:5:5:5:5:5:8; malar space 0.16 eye height; ovipositor length 2.2 $\mathrm{mm}$.

Body predominantly reddish brown except apex of antenna (F10-F13) and metasomal terga 2-7 infused with black; F6-F8 yellowish brown; wing venation dark brown; wing membrane hyaline except amorphous infused patch along basal vein and another below stigma; ovipositor sheaths dark brown; ovipositor yellowish brown.

Paratype female: Essentially as in holotype except F9 apically infused with black; F6-F8 more yellow. 


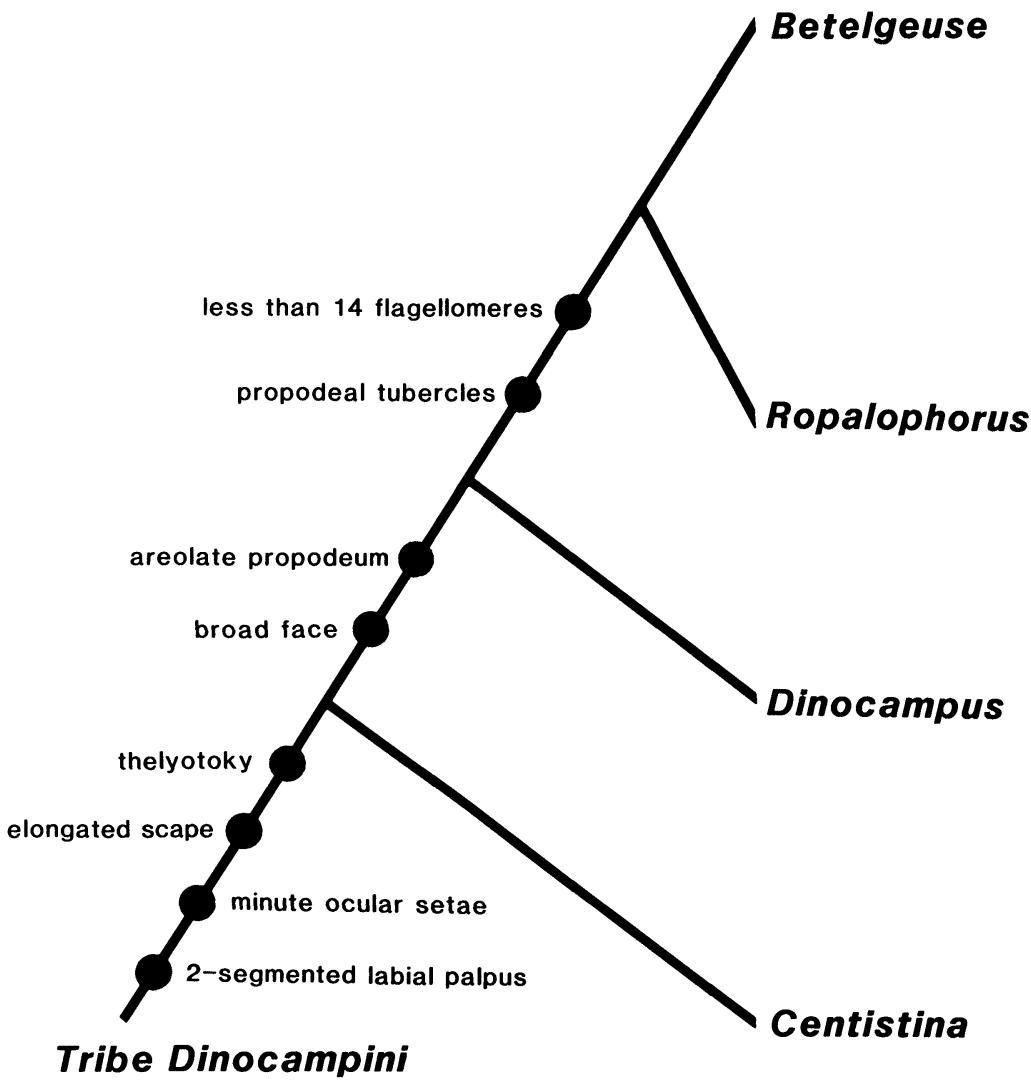

Fig. 4. Hypothesis of relationships among genera of the tribe Dinocampini. See text for discussion.

Male: Unknown.

Paratype data: 1 female, same data as holotype [Museum of Comparative Zoology, Cambridge].

Host: Unknown; however, the host is probably an adult beetle since other dinocampine species (sensu Shaw 1985) parasitize adult beetles (Shaw 1985, 1988).

Distribution: Known only from the type locality in Durango, Mexico.

Etymology: The specific epithet refers to the Aztec indian tribe in Mexico. 


\section{ACKNOWLEDGMENTS}

Figures 1-3 were prepared by Ms. Kathy Brown-Wing, who deserves much credit, especially for the care and meticulous detail applied to the habitus illustration. Thanks are due to Dr. M. Sharkey, Biosystematics Research Centre, Agriculture Canada, Ottawa, Ontario, for arranging the loan of these remarkable specimens and also for critiquing the manuscript. Additional thanks to Dr. P. M. Marsh, Systematic Entomology Laboratory, U.S. Department of Agriculture, c/o National Museum of Natural History, Washington D.C., who reviewed the manuscript as well, and provided many helpful comments. Special thanks are due to Dr. W. R. M. Mason, Biosystematics Research Centre, Agriculture Canada, Ottawa, Ontario, for collecting the specimens, recognizing their significance as a new euphorine genus, and calling them to my attention in the first place.

\section{SUMMARY}

Betelgeuse aztecus Shaw, a new euphorine braconid genus and species from Mexico is described and illustrated. Reasons for placing it in the tribe Dinocampini are given, and its phylogenetic position relative to other genera in that tribe is discussed.

\section{Literature Cited}

ACHTERBerg, C. vaN

1974. The features of the petiolar segment in some Braconidae. Ent. Berich. 34: 213.

BalduF, W. V.

1926. Bionomics of Dinocampus coccinellae (Schrank). Ann. Entomol. Soc. Amer. 19: 465-498.

DAvid, M. H., AND G. WILDE

1973. Susceptibility of the convergent lady beetle to parasitism by Perilitus coccinellae (Schrank) (Hymenoptera: Braconidae). J. Kans. Entomol. Soc. 46: 359-362.

HARRIS, R. A.

1979. A glossary of surface sculpturing. Occasional Papers in Entomology, No. 28. State of California, Dept. of Food and Agriculture, Sacramento. $31 \mathrm{pp}$.

LOAN, C. C.

1983. Host and generic relations of the Euphorini (Hymenoptera: Braconidae).

Contrib. Amer. Entomol. Inst. 20: 388-397. 
Marsh, P. M., S. R. Shaw, and R. A. Wharton.

1987. An identification manual for the North American genera of the family Braconidae (Hymenoptera). Mem. Entomol. Soc. Wash., No. 13, Washington, D.C. 98 pp.

MueseBeCK, C. F. W.

1936. The genera of parasitic wasps of the braconid subfamily Euphorinae (Hymenoptera), with a review of the Nearctic species. United States Department of Agriculture Miscellaneous Publication No. 241. Washington, D.C. $38 \mathrm{pp}$.

1955. A remarkable new species of Perilitus from Mexico (Hymenoptera: Braconidae). Proc. Biol. Soc. Wash. 68: 143-144.

1963. Host relations of the Euphorini (Hymenoptera: Braconidae). Proc. Entomol. Soc. Wash. 65: 306.

Obrycki, J. J., M. J. Tauber and C. A. Tauber

1985. Perilitus coccinellae (Hymenoptera: Braconidae): parasitization and development in relation to host-stage attacked. Ann. Entomol. Soc. Amer. 78: 852-854.

Semyanov, V. P.

1979. An unusual instance of parasitism in Dinocampus coccinellae (Hymenoptera: Braconidae). Entomol. Rev. Wash. 57: 351-352.

Shaw, S. R.

1985. A phylogenetic study of the subfamilies Meteorinae and Euphorinae (Hymenoptera: Braconidae). Entomography 3: 277-370.

1987. Orionis, a new genus from Central America, with an analysis of its phylogenetic placement in the tribe Euphorini (Hymenoptera: Braconidae). Syst. Ent. 12: 103-109.

1988. Euphorine phylogeny: the evolution of diversity in host-utilization by parasitoid wasps (Hymenoptera: Braconidae). Ecol. Ent. 13: 323-335.

ShENEFELT, R. D.

1960. Ropalophorus Haliday-a genus new to North America (Hymenoptera: Braconidae: Euphorinae). Ann. Entomol. Soc. Amer. 53: 542-546.

1980. Hymenopterorum catalogus, part 16. Braconidae 11. Introduction, guide to host names, and index to braconid names. W. Junk, The Hague, Netherlands. $384 \mathrm{pp}$.

Sмiтн, B. C.

1960. Note on the parasitism of two coccinellids, Coccinella trifasciata perplexa Muls. and Coleomegilla maculata lengi Timb. (Coleoptera: Coccinellidae) in Ontario. Can. Ent. 92: 652.

ToBias, V. I.

1966. Generic groupings and evolution of parasitic Hymenoptera of the subfamily Euphorinae (Hymenoptera: Braconidae). II. Ent. Obozr. 45: 612-633. Translation in Entomol. Rev. Wash. 45: 348-358. 

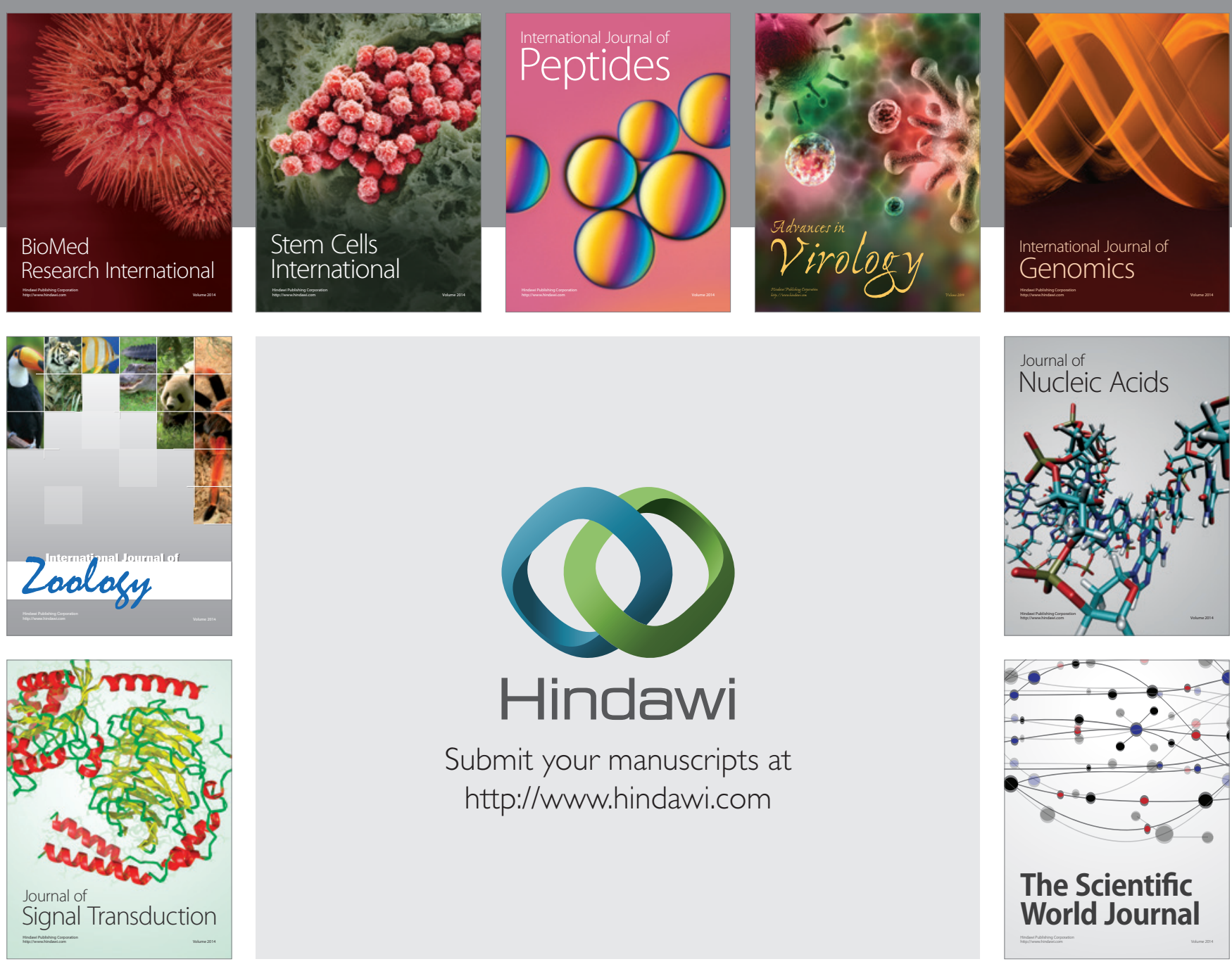

Submit your manuscripts at

http://www.hindawi.com
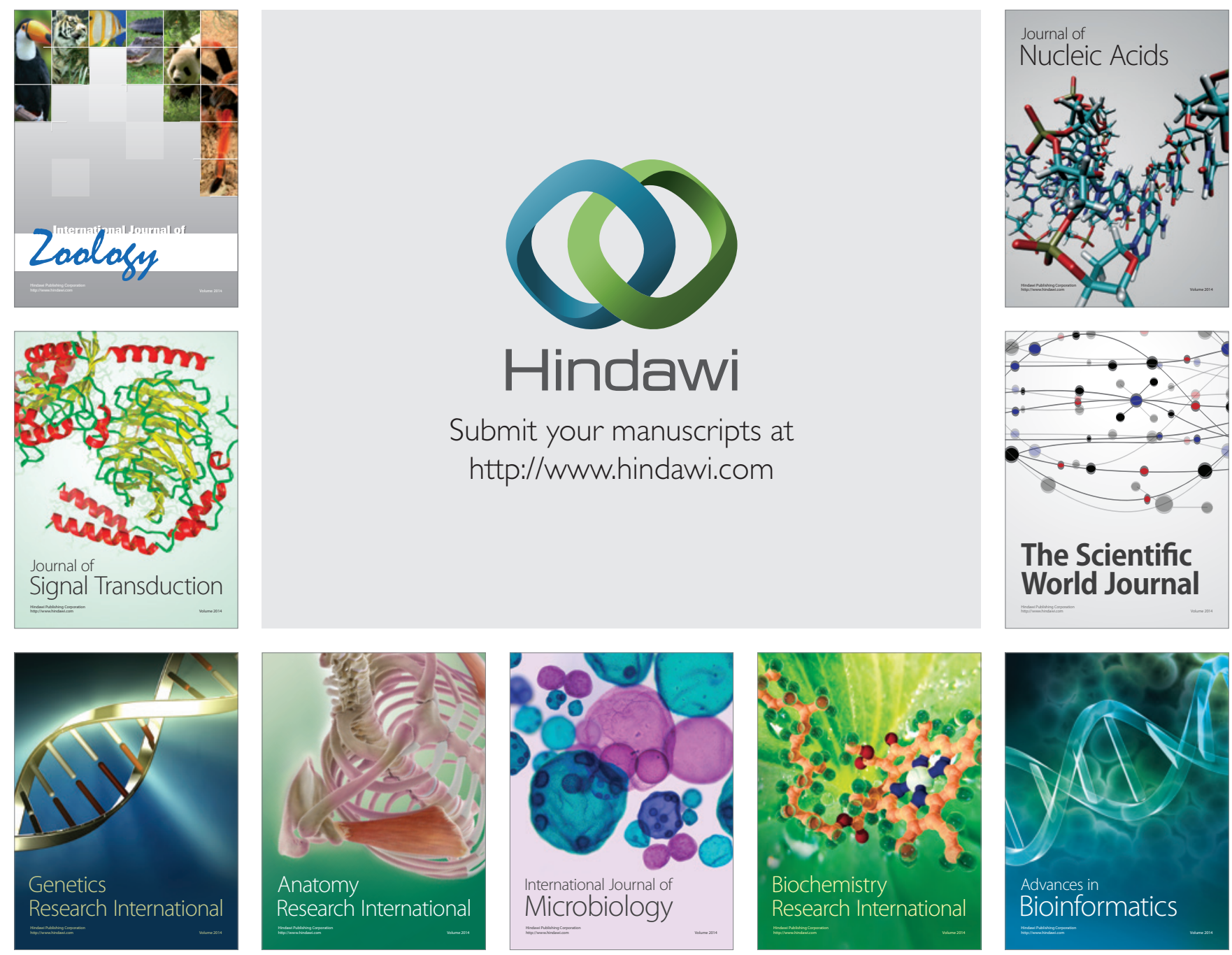

The Scientific World Journal
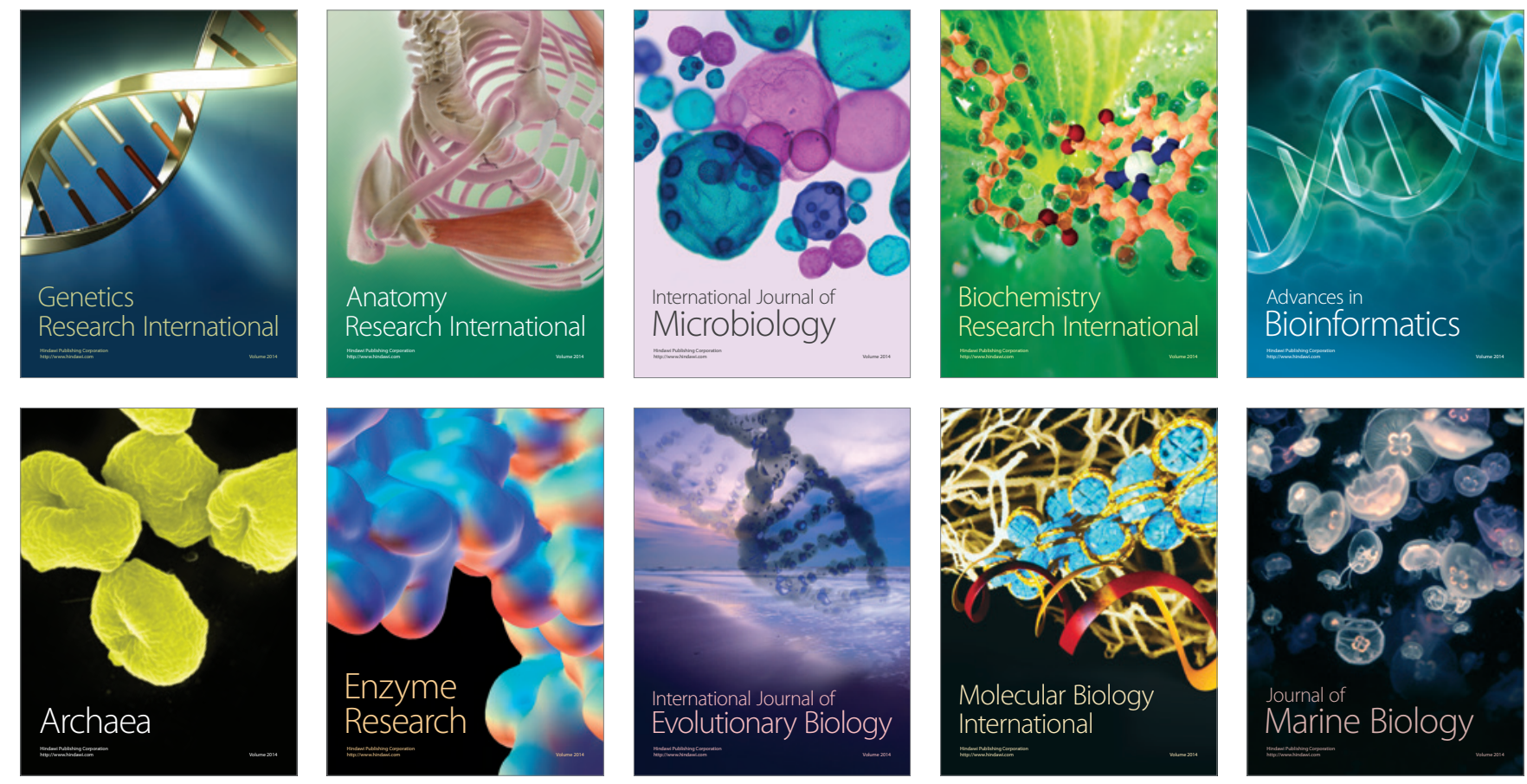